\title{
ATUAÇÃO DO ENFERMEIRO DO TRABALHO NA REDUÇÃO DE RISCOS BIOLÓGICOS NO ÂMBITO HOSPITALAR
}

\author{
PERFORMANCE OF THE WORK NURSE IN THE REDUCTION OF BIOLOGICAL RISKS IN THE \\ HOSPITAL ENVIRONMENT
}

\author{
Claudemir Santos de Jesus ${ }^{\mathrm{a}^{*}}$, Izabella dos Santos Pinto ${ }^{\mathrm{b}^{* *}}$, Joyce Leandro Benevenuto dos Reis ${ }^{\mathrm{c}^{*}}$, \\ Joyce Fernandes $^{\mathrm{d} *}$, Rafael dos Santos ${ }^{\mathrm{e}^{* * *}}$, Edvânia Santos Soares ${ }^{\mathrm{f***}}$ \\ audemi34@gmail.com, bBebel527@hotmail.com, cjoyceleandro30@gmail.com, dfernandesjoyce93@gmail.com, \\ eenfermeirorafaelsantos@gmail.com, ${ }^{\mathrm{f}}$ edvania@promolife.com.br \\ *Faculdade de Duque de Caxias - Duque de Caxias (RJ), Brasil \\ **Universidade Veiga de Almeida - Rio de Janeiro (RJ), Brasil \\ ***UNISUAM - Rio de Janeiro (RJ), Brasil \\ ****Universidade Estadual do Rio de Janeiro - Rio de Janeiro (RJ), Brasil
}

Data de recebimento do artigo: 21/07/2017 Data de aceite do artigo: 07/08/2017

\section{RESUMO}

Introduçáo: A equipe de enfermagem está exposta aos acidentes com materiais biológicos no ambiente hospitalar, o que ressalta a importância das capacitações e atenção nos procedimentos e açóes dos profissionais. Objetivo: Analisar a atuação do enfermeiro do trabalho para a redução do risco biológico no âmbito hospitalar. Métodos: Trata-se de uma revisão integrativa, com abordagem qualitativa descritiva, com a questão de pesquisa: Qual a atuação do enfermeiro do trabalho para a redução do risco biológico no âmbito hospitalar? Resultados: A pesquisa obteve como resultado 14 artigos, que evidenciaram a necessidade de implementar a educaçáo permanente, com foco nas práticas reflexivas, para centralizar os treinamentos pontuais a fim de que o trabalhador obtenha as instruçóes de como proceder no cotidiano. Conclusão: $\mathrm{O}$ enfermeiro do trabalho contribui significativamente no âmbito hospitalar ao desenvolver açôes de medidas de segurança, deteç̧ão, minimização dos riscos ocupacionais e agravos biológicos, aos quais estão expostos os profissionais de enfermagem durante a assistência.

Palavras-chave: Enfermagem do trabalho; riscos ocupacionais; acidentes de trabalho; saúde do trabalhador.

\section{ABSTRACT}

Introduction: The nursing team is exposed to accidents with biological materials in the hospital environment, which highlights the importance of training and attention in the procedures and actions of professionals. Objective: Analyze the role of the occupational nurse in reducing the biological risk in the hospital setting. Methods: This is an integrative review, with descriptive qualitative approach, with the research question: What is the occupational nurse's role in reducing the biological risk in the hospital? Results: The research resulted in 14 articles, which evidenced the need to implement permanent education, focusing on reflective practices, to centralize the occasional training, so that the worker obtains instructions on how to proceed in the daily life. Conclusion: The occupational nurse contributes significantly in the hospital environment by developing actions of safety measures, detection and minimization of occupational hazards and biological injuries to which nursing professionals are exposed during the care, aiming to improve working conditions.

Keywords: Occupational health nursing; occupational risks; occupational accidents; worker health. 


\section{Introdução}

O trabalhador da saúde está exposto aos riscos biológicos, que são causadores de vários agravos ocupacionais ou náo, ao executarem atividades no cuidado direto e indireto a clientela, por estarem expostos às infecçóes transmitidas pelo sangue ou em outros fluidos orgânicos, tanto que dentre os acidentes no ambiente hospitalar se destacam os que acontecem com materiais perfurocortantes, que têm sido reconhecidos como um dos principais problemas de exposição aos trabalhadores à contaminação e riscos mecânicos ${ }^{1,2,3}$.

$\mathrm{Na}$ legislaçáo brasileira, os riscos ocupacionais são classificados como físicos, químicos e biológicos presentes no ambiente de trabalho que, dependendo da natureza, concentração ou intensidade e tempo de exposição, são susceptíveis de causar danos aos trabalhadores ${ }^{4}$.

Em 1996, os Centers for Disease Control and Prevention publicaram a rotina de isolamento e precauçóes, sendo recomendadas as precauçóes-padrão, que deverão ser aplicadas no atendimento aos pacientes hospitalizados, independentemente do estado de infecçáo, pois os equipamentos de proteçáo individual (EPIs) visam interromper a cadeia de transmissáo dos microrganismos ${ }^{5,6}$.

A enfermagem, todavia, integra a área de Saúde do Trabalhador e tem o campo de atuação prática, especialmente o Serviço Especializado em Segurança e Medicina do Trabalho de empresas, buscando aprofundar e desenvolver conhecimentos e ampliar seu papel junto à área de saúde do trabalhador ${ }^{7}$.

De acordo com a Associação Nacional dos Enfermeiros do Trabalho, em território nacional, os profissionais desempenham atividades como higiene ocupacional, segurança e medicina, integram grupos de estudo de proteção da saúde e segurança do trabalhador. As responsabilidades incluem diversas açóes relacionadas à prevenção de doenças e acidentes de trabalho, como também à promoção da saúde no trabalho ${ }^{8}$.

O tema foi escolhido devido à elevada exposição dos profissionais de enfermagem aos resíduos biológicos. Apesar de esse tipo de exposição ser intensivamente abordado, ainda é notória a baixa aplicabilidade das medidas preventivas para redução do risco ocupacional. $\mathrm{O}$ profissional é responsável pela melhoria das condiçóes laborais e pela segurança dos trabalhadores da equipe de enfermagem expostos a riscos biológicos. Dessa forma, o estudo tem como objetivo analisar a atuação do enfermeiro do trabalho para a redução do risco biológico no âmbito hospitalar.

\section{Metodologia}

Trata-se de uma revisão integrativa, com abordagem qualitativa de caráter descritivo. Teve como objetivo contribuir para a educação dos profissionais de enfermagem voltada para a reduçáo dos riscos ocupacionais relacionados ao risco biológico?

$\mathrm{Na}$ primeira fase, ocorreu a elaboração da questáo norteadora de pesquisa, que é: Qual a atuação do enfermeiro do trabalho para a redução do risco biológico no âmbito hospitalar?

$\mathrm{Na}$ segunda fase, iniciou-se uma intensa busca na literatura, sendo definidos os critérios de inclusão: artigos disponíveis em português, no período de 2012 a 2016, com os descritores, que são: "enfermagem"; "riscos ocupacionais"; e "saúde do trabalhador", através da (BVS) na base de dados BDENF, sendo focada a pesquisa na literatura disponível de textos completos em português.

Após a realização da busca nos bancos de dados com as palavras associadas, foi feita uma leitura seletiva dos artigos encontrados na mesma, analisando quais bibliográficas atendiam à problemática da nossa pesquisa, para que fosse formada nossa bibliografia potencial, sendo descartados aqueles que náo estavam relacionados com o tema e os repetidos.

Entáo, escolhemos as pesquisas de acordo com os objetivos propostos e critérios de inclusão e exclusão dos artigos, alcançando a bibliografia potencial formada por 14 artigos selecionados para análise dos dados.

Ao cruzar os descritores "enfermagem" AND "riscos ocupacionais" AND "saúde do trabalhador" obtivemos o total de 771, com os critérios de inclusão e exclusão sistematizados evidenciou 20 , sendo selecionados 2.

Ao cruzar os descritores "enfermagem" AND "riscos ocupacionais", obtivemos o total de 1.562, com os critérios de inclusão e exclusão sistematizados evidenciou 28, sendo selecionados 3 .

Ao utilizar os descritores "enfermagem" AND "saúde do trabalhador", obtivemos 11.986, ao filtrarmos, obtivemos 265, mas para fechar um pouco mais o filtro, utilizamos os assuntos principais "enfermagem"; "saúde do trabalhador"; "masculino"; "feminino", com o limite "adulto", evidenciando 176 produçóes, das quais selecionamos 5 .

Ao cruzar os descritores "riscos ocupacionais" AND "saúde do trabalhador", obtivemos o total de 4.403, com os critérios de inclusão e exclusão sistematizados, 47 foram evidenciados, sendo seleciona$\operatorname{dos} 4$. 
Quadro 1: Levantamento estrutural dos artigos selecionados na Biblioteca Virtual em Saúde

\begin{tabular}{|c|c|c|c|c|c|c|}
\hline Título & Periódicos & Base de dados & Ano & Local & Profissáo do autor & Tipo de produçáo \\
\hline $\begin{array}{l}\text { Análise dos acidentes de trabalho na } \\
\text { equipe de enfermagem: uma revisáo } \\
\text { integrativa }^{10}\end{array}$ & $\begin{array}{l}\text { Revista de } \\
\text { Pesquisa: } \\
\text { Cuidado é } \\
\text { Fundamental }\end{array}$ & BDENF & 2016 & MG & Enfermeiro & Artigo de revisão \\
\hline $\begin{array}{l}\text { Riscos de acidentes com materiais perfu- } \\
\text { rocortantes no setor de urgência de um } \\
\text { hospital público }^{11}\end{array}$ & $\begin{array}{l}\text { Revista de } \\
\text { Pesquisa: } \\
\text { Cuidado é } \\
\text { Fundamental }\end{array}$ & BDENF & 2016 & RN & Enfermeiro & Artigo original \\
\hline $\begin{array}{l}\text { Acidente com material biológico: uma } \\
\text { abordagem a partir da análise das ativida- } \\
\text { des de trabalho }{ }^{12}\end{array}$ & $\begin{array}{l}\text { Saúde e } \\
\text { Sociedade }\end{array}$ & LILACS & 2015 & $\mathrm{SP}$ & Enfermeiro & Artigo original \\
\hline $\begin{array}{l}\text { Fatores de risco à segurança do enfermeiro } \\
\text { na Unidade de Terapia Intensiva de um } \\
\text { hospital geral }^{13}\end{array}$ & $\begin{array}{l}\text { Revista } \\
\text { Brasileira de } \\
\text { Ciências da } \\
\text { Saúde }\end{array}$ & LILACS & 2015 & $\mathrm{~PB}$ & $\begin{array}{l}\text { Enfermeiro/ } \\
\text { Odontologia }\end{array}$ & Artigo original \\
\hline $\begin{array}{l}\text { Clima de segurança no trabalho hospitalar: } \\
\text { adaptaçáo de medida (ClimaSeg-H })^{14}\end{array}$ & $\begin{array}{l}\text { Avaliação } \\
\text { Psicológica }\end{array}$ & LILACS & 2015 & ES & Psicólogo & Artigo original \\
\hline $\begin{array}{l}\text { A unidade dialítica como um cenário de } \\
\text { exposiçáo a riscos }{ }^{15}\end{array}$ & $\begin{array}{l}\text { Revista de } \\
\text { Pesquisa: } \\
\text { Cuidado é } \\
\text { Fundamental }\end{array}$ & LILACS & 2014 & RGS & Enfermeiro & Artigo original \\
\hline $\begin{array}{l}\text { Riscos ocupacionais e a saúde do tra- } \\
\text { balhador de enfermagem - buscando } \\
\text { evidências }^{16}\end{array}$ & $\begin{array}{l}\text { Revista de } \\
\text { Pesquisa: } \\
\text { Cuidado é } \\
\text { Fundamental }\end{array}$ & LILACS & 2014 & RS & Enfermeiro & $\begin{array}{l}\text { Artigo de revisão } \\
\text { integrativa }\end{array}$ \\
\hline $\begin{array}{l}\text { Acidentes de trabalho com material bio- } \\
\text { lógico ocorridos em municípios de Minas } \\
\text { Gerais }^{17}\end{array}$ & $\begin{array}{l}\text { Revista } \\
\text { Brasileira de } \\
\text { Enfermagem }\end{array}$ & LILACS & 2014 & MG & Enfermeiro & Artigo de revisão \\
\hline $\begin{array}{l}\text { O enfermeiro do trabalho na identifica- } \\
\text { çáo dos riscos ocupacionais em medicina } \\
\text { hiperbárica }^{18}\end{array}$ & $\begin{array}{l}\text { Revista de } \\
\text { Pesquisa: } \\
\text { Cuidado é } \\
\text { Fundamental }\end{array}$ & LILACS & 2014 & $\mathrm{RJ}$ & Enfermeiro & Artigo original \\
\hline $\begin{array}{l}\text { Fatores de riscos para acidentes com mate- } \\
\text { riais perfurocortantes }{ }^{19}\end{array}$ & $\begin{array}{l}\text { O Mundo da } \\
\text { Saúde }\end{array}$ & LILACS & 2013 & PR & Enfermeiro & Artigo original \\
\hline $\begin{array}{l}\text { Acidentes com material biológico em } \\
\text { trabalhadores de enfermagem do Hospital } \\
\text { Geral de Palmas (TO })^{20}\end{array}$ & $\begin{array}{l}\text { Revista } \\
\text { Brasileira } \\
\text { de Saúde } \\
\text { Ocupacional }\end{array}$ & SCIELO & 2013 & TO & Enfermeiro & Artigo original \\
\hline $\begin{array}{l}\text { Riscos e doenças ocupacionais do docente } \\
\text { universitário de enfermagem: implicaçóes } \\
\text { na saúde do trabalhador }{ }^{21}\end{array}$ & $\begin{array}{l}\text { Revista de } \\
\text { Pesquisa: } \\
\text { Cuidado é } \\
\text { Fundamental }\end{array}$ & LILACS & 2013 & RJ & Enfermeiro & Artigo original \\
\hline $\begin{array}{l}\text { Caracterizaçáo das exposiçóes ocupacionais } \\
\text { a material biológico entre trabalhadores de } \\
\text { hospitais no município de Teresina, estado } \\
\text { do Piauí, Brasil, } 2007 \text { a } 2011^{22}\end{array}$ & $\begin{array}{l}\text { Epidemiologia } \\
\text { e Serviços de } \\
\text { Saúde }\end{array}$ & LILACS & 2013 & PI & Enfermeiro & $\begin{array}{l}\text { Estudo descritivo } \\
\text { (Sinan) }\end{array}$ \\
\hline $\begin{array}{l}\text { Riscos ocupacionais e mecanismos de } \\
\text { autocuidado do trabalhador de um centro } \\
\text { de material e esterilizaçáo } \\
\end{array}$ & $\begin{array}{l}\text { Revista } \\
\text { Gaúcha de } \\
\text { Enfermagem }\end{array}$ & LILACS & 2012 & RS & Enfermeiro & Artigo original \\
\hline
\end{tabular}

Fonte: Artigos coletados na Biblioteca Virtual em Saúde, em janeiro de 2017. 
O Quadro 1 relata os estudos que compuseram esta revisão integrativa no que se referiu ao periódico ou à editora por ordem alfabética, à base de dados, ao local, à profissão do autor, ao título, ao objetivo, ao tipo de pesquisa, ao tipo de produção e síntese.

Desse modo, encontrou-se os artigos nas bases de dados SCIELO (1), BDENF (2) e LILACS (11), em relação aos periódicos: Revista de Pesquisa - Cuidado é Fundamental; Saúde e Sociedade; Revista Brasileira de Ciências da Saúde; Avaliação Psicológica; O Mundo da Saúde; Revista Brasileira de Saúde Ocupacional; Epidemiologia e Serviços de Saúde; Revista Gaúcha de Enfermagem.

Em relação ao recorte temporal, foi encontrado artigos nos anos de 2012 (1); 2013 (4); 2014 (4); 2015 (3); 2016 (2). Já em relação ao local do estudo, tivemos uma representatividade de produçóes nos seguintes estados MG (2); RN (1); SP (1); PB (1); ES (1); RGS (1); RS (2); RJ (1); PR (1); TO (1); PI (1).
$\mathrm{Na}$ quarta etapa, os artigos foram selecionados para revisão integrativa, em que se verificou autenticidade, qualidade metodológica, importância das informaçóes e representatividade.

Os artigos selecionados foram separados por seus títulos, seus objetivos, seus dados evidenciados e seu nível de evidência. A análise foi baseada nos níveis 3: evidências de estudos quase-experimentais; 4: evidências de estudos descritivos (não experimentais) ou com abordagem qualitativa; e 6: evidências baseadas em opinióes de especialistas.

A quinta etapa consistiu na realização da interpretação e discussão dos dados e resultados encontrados que estavam relacionados com o referencial teórico. Assim, a análise dos dados foi realizada, baseada nos artigos selecionados, em que foi possível aglomerar o conhecimento produzido através da temática nesta revisão para obtermos a síntese do estudo ${ }^{23}$.

Quadro 2: Validação dos artigos selecionados conforme os níveis de evidências dos estudos.

\begin{tabular}{|c|c|c|c|c|}
\hline Título & Objetivos & Tipo de pesquisa & Dados evidenciados & Nível de evidência \\
\hline $\begin{array}{l}\text { Análise dos acidentes de } \\
\text { trabalho na equipe de } \\
\text { enfermagem: uma revisão } \\
\text { integrativa }^{10}\end{array}$ & $\begin{array}{l}\text { Analisar os acidentes de traba- } \\
\text { lho na equipe de enfermagem. }\end{array}$ & Revisão integrativa & $\begin{array}{l}\text { Fica evidenciado que os traba- } \\
\text { lhadores devem ter os cuidados } \\
\text { para evitar acidente no local de } \\
\text { trabalho, mas também o emprega- } \\
\text { dor deve cumprir suas obrigaçôes } \\
\text { visando à proteçáo do trabalhador. }\end{array}$ & 04 \\
\hline $\begin{array}{l}\text { Riscos de acidentes com } \\
\text { materiais perfurocortan- } \\
\text { tes no setor de urgência } \\
\text { de um hospital público }{ }^{11}\end{array}$ & $\begin{array}{l}\text { Conhecer os fatores de risco } \\
\text { relacionados aos acidentes com } \\
\text { material perfurocortante pre- } \\
\text { sente no trabalho dos técnicos } \\
\text { de enfermagem do setor de } \\
\text { atendimento de urgência de } \\
\text { um hospital público. }\end{array}$ & $\begin{array}{l}\text { Pesquisa descriti- } \\
\text { va, de abordagem } \\
\text { qualitativa }\end{array}$ & $\begin{array}{l}\text { As condições de trabalho no setor } \\
\text { de urgência necessitam serem revis- } \\
\text { tas a fim de oferecer um ambiente } \\
\text { adequado para minimizar os riscos } \\
\text { ocupacionais durante os procedi- } \\
\text { mentos de enfermagem. }\end{array}$ & 04 \\
\hline $\begin{array}{l}\text { Acidente com mate- } \\
\text { rial biológico: uma } \\
\text { abordagem a partir da } \\
\text { análise das atividades de } \\
\text { trabalho }{ }^{12}\end{array}$ & $\begin{array}{l}\text { Analisar o trabalho de auxilia- } \\
\text { res e técnicos de enfermagem, } \\
\text { categoria mais numerosa entre } \\
\text { os profissionais de saúde e } \\
\text { mais sujeita à incidência de } \\
\text { acidentes de trabalho. }\end{array}$ & Estudo qualitativo & $\begin{array}{l}\text { Revelaram que as rotinas de tra- } \\
\text { balho são caracterizadas por rol de } \\
\text { tarefas de cuidados aos pacientes, } \\
\text { marcado por grande variabilidade } \\
\text { no cotidiano das atividades cons- } \\
\text { tantemente interrompidas com so- } \\
\text { breposição de tarefas decorrentes. }\end{array}$ & 04 \\
\hline $\begin{array}{l}\text { Fatores de risco à se- } \\
\text { gurança do enfermeiro } \\
\text { na Unidade de Terapia } \\
\text { Intensiva de um hospital } \\
\text { geral }^{13}\end{array}$ & $\begin{array}{l}\text { Identificar os fatores de } \\
\text { riscos aos quais o enfermeiro } \\
\text { intensivista está exposto e que } \\
\text { podem ocasionar acidentes de } \\
\text { trabalho. }\end{array}$ & $\begin{array}{l}\text { Abordagem } \\
\text { indutiva }\end{array}$ & $\begin{array}{l}\text { Foram identificados riscos biológi- } \\
\text { cos, físicos, químicos e ergonômi- } \\
\text { cos, associados aos esforços repeti- } \\
\text { dos, como o risco ocupacional pelo } \\
\text { ritmo de trabalho excessivo. }\end{array}$ & 06 \\
\hline $\begin{array}{l}\text { Clima de segurança no } \\
\text { trabalho hospitalar: } \\
\text { adaptaçáo de medida } \\
(\text { ClimaSeg-H })^{14}\end{array}$ & $\begin{array}{l}\text { A adaptação de uma medida, } \\
\text { além de buscar explorar a rela- } \\
\text { ção das dimensóes encontradas } \\
\text { com aspectos de trabalho em } \\
\text { contextos hospitalares. }\end{array}$ & Pesquisa de campo & $\begin{array}{l}\text { A compreensão e a percepção dos } \\
\text { trabalhadores dos aspectos de segu- } \\
\text { rança no trabalho como ferramenta } \\
\text { de investigação dos determinantes } \\
\text { de risco na atividade de trabalho } \\
\text { para a sugestão de novas políticas } \\
\text { e estratégias de gerenciamento de } \\
\text { risco, para favorecer a qualidade de } \\
\text { vida e de saúde no trabalho. }\end{array}$ & 04 \\
\hline
\end{tabular}


Quadro 2: Continuação.

\begin{tabular}{|c|c|c|c|c|}
\hline Título & Objetivos & Tipo de pesquisa & Dados evidenciados & Nível de evidência \\
\hline $\begin{array}{l}\text { A unidade dialítica como } \\
\text { um cenário de exposiçáo } \\
\text { a riscos }{ }^{15}\end{array}$ & $\begin{array}{l}\text { Identificar concepçóes dos } \\
\text { profissionais de saúde de uma } \\
\text { unidade dialítica acerca dos } \\
\text { riscos a que estão expostos. }\end{array}$ & $\begin{array}{l}\text { Pesquisa descritiva } \\
\text { de abordagem } \\
\text { qualitativa }\end{array}$ & $\begin{array}{l}\text { Percebeu-se que investimentos em } \\
\text { educação, saúde e medidas saudáveis } \\
\text { de trabalho, configuram meios de } \\
\text { promoção à saúde do trabalhador. }\end{array}$ & 04 \\
\hline $\begin{array}{l}\text { Riscos ocupacionais e a } \\
\text { saúde do trabalhador de } \\
\text { enfermagem - buscando } \\
\text { evidências }^{16}\end{array}$ & $\begin{array}{l}\text { Identificar a produção cientí- } \\
\text { fica nacional e internacional } \\
\text { acerca dos riscos ocupacionais } \\
\text { da equipe de enfermagem que } \\
\text { atua no âmbito hospitalar. }\end{array}$ & Revisão integrativa & $\begin{array}{l}\text { Apontou que mesmo com conhe- } \\
\text { cimento constante dos riscos no } \\
\text { trabalho de enfermagem, não há } \\
\text { aderência das medidas de proteção, } \\
\text { surgindo a lacuna do conhecimento } \\
\text { e a fragilidade das açóes educativas. }\end{array}$ & 06 \\
\hline $\begin{array}{l}\text { Acidentes de trabalho } \\
\text { com material biológico } \\
\text { ocorridos em municípios } \\
\text { de Minas Gerais }{ }^{17}\end{array}$ & $\begin{array}{l}\text { Identificar o perfil dos aciden- } \\
\text { tes com exposiçáo a material } \\
\text { biológico ocorridos em Minas } \\
\text { Gerais. }\end{array}$ & $\begin{array}{l}\text { Pesquisa descritiva } \\
\text { transversal }\end{array}$ & $\begin{array}{l}\text { Os resultados subsidiarão o plane- } \\
\text { jamento de açóes preventivas e de } \\
\text { novas condutas diante da ocorrência } \\
\text { de acidentes com material biológico. }\end{array}$ & 03 \\
\hline $\begin{array}{l}\text { O enfermeiro do traba- } \\
\text { lho na identificaçáo dos } \\
\text { riscos ocupacionais em } \\
\text { medicina hiperbárica }\end{array}$ & $\begin{array}{l}\text { Elaborar o mapa de risco; } \\
\text { identificar os riscos ocupacio- } \\
\text { nais ao trabalhador da clínica de } \\
\text { medicina hiperbárica; descrever } \\
\text { açóes/ medidas preventivas do } \\
\text { enfermeiro do trabalho para } \\
\text { minimizar os riscos existentes. }\end{array}$ & $\begin{array}{l}\text { Pesquisa descritiva } \\
\text { e exploratória } \\
\text { com abordagem } \\
\text { qualitativa }\end{array}$ & $\begin{array}{l}\text { Elaborou-se um mapa de riscos } \\
\text { para o diagnóstico dos riscos } \\
\text { ocupacionais e consequentemente } \\
\text { para o planejamento de medidas } \\
\text { preventivas, que visaram à promo- } \\
\text { çáo da saúde dos trabalhadores. }\end{array}$ & 03 \\
\hline $\begin{array}{l}\text { Fatores de riscos para } \\
\text { acidentes com materiais } \\
\text { perfuro cortantes }^{19}\end{array}$ & $\begin{array}{l}\text { Identificar os fatores de risco } \\
\text { para acidentes com material } \\
\text { perfurocortantes e analisar as } \\
\text { principais causas referidas. }\end{array}$ & $\begin{array}{l}\text { Pesquisa explo- } \\
\text { ratória de caráter } \\
\text { retrospectivo }\end{array}$ & $\begin{array}{l}\text { Identificou as causas possíveis para } \\
\text { os fatores de risco dos acidentes e } \\
\text { a importância da implementação } \\
\text { da Política Nacional de Educação } \\
\text { Permanente em Saúde. }\end{array}$ & 03 \\
\hline $\begin{array}{l}\text { Acidentes com material } \\
\text { biológico em trabalha- } \\
\text { dores de enfermagem do } \\
\text { Hospital Geral de Palmas } \\
(\mathrm{TO})^{20}\end{array}$ & $\begin{array}{l}\text { Identificar os acidentes de } \\
\text { trabalho com material biológico } \\
\text { ocorridos com os trabalhadores } \\
\text { de enfermagem do Hospital } \\
\text { Geral de Palmas (HGP) e verifi- } \\
\text { car a ocorrência de subnotifica- } \\
\text { ção no Serviço de Segurança do } \\
\text { Trabalho (SST) do HGP }\end{array}$ & $\begin{array}{l}\text { Pesquisa descritiva } \\
\text { transversal }\end{array}$ & $\begin{array}{l}\text { Identificou necessidade de refor- } \\
\text { mulaçáa do protocolo de encami- } \\
\text { nhamento para o atendimento ao } \\
\text { acidentado e participaçáo efetiva } \\
\text { dos profissionais de enfermagem. }\end{array}$ & 03 \\
\hline $\begin{array}{l}\text { Riscos e doenças ocu- } \\
\text { pacionais do docente } \\
\text { universitário de enfer- } \\
\text { magem: implicaçóes na } \\
\text { saúde do trabalhador }{ }^{21}\end{array}$ & $\begin{array}{l}\text { Identificar as condiçóes do } \\
\text { trabalho e os motivos de afasta- } \\
\text { mento do docente universitário } \\
\text { de enfermagem; analisar os } \\
\text { riscos e as doenças ocupacionais } \\
\text { e propor medidas de prevenção } \\
\text { aos docentes de enfermagem. }\end{array}$ & $\begin{array}{l}\text { Pesquisa descritiva } \\
\text { e exploratória, } \\
\text { com abordagem } \\
\text { quantiqualitativa }\end{array}$ & $\begin{array}{l}\text { Proporcionar aos trabalhadores da } \\
\text { educação melhoria das condiçôes } \\
\text { de saúde, como a importância de } \\
\text { intervir, com práticas de atividades } \\
\text { físicas e de lazer, orientaçóes do } \\
\text { uso adequado da voz, implementar } \\
\text { mudanças organizacionais e das } \\
\text { condiçôes de trabalho. }\end{array}$ & 04 \\
\hline $\begin{array}{l}\text { Caracterizaçáo das ex- } \\
\text { posiçóes ocupacionais a } \\
\text { material biológico entre } \\
\text { trabalhadores de hos- } \\
\text { pitais no município de } \\
\text { Teresina, estado do Piauí, } \\
\text { Brasil, } 2007 \text { a } 2011^{22}\end{array}$ & $\begin{array}{l}\text { Descrever as exposições ocu- } \\
\text { pacionais a material biológico } \\
\text { (EOMB) em hospitais do } \\
\text { município de Teresina, estado } \\
\text { do Piauí, Brasil, no período de } \\
2007 \text { a } 2011 .\end{array}$ & Pesquisa descritiva & $\begin{array}{l}\text { Percebeu-se a vulnerabilidade dos } \\
\text { profissionais de saúde à ocorrên- } \\
\text { cia de exposiçóes ocupacionais a } \\
\text { material biológico, principalmente } \\
\text { os da enfermagem, sendo neces- } \\
\text { sário intensificar as estratégias de } \\
\text { prevenção nos profissionais. }\end{array}$ & 03 \\
\hline $\begin{array}{l}\text { Riscos ocupacionais e } \\
\text { mecanismos de autocui- } \\
\text { dado do trabalhador de } \\
\text { um centro de material e } \\
\text { esterilizaçáo }^{23}\end{array}$ & $\begin{array}{l}\text { Investigar riscos ocupacionais } \\
\text { e mecanismos de autocuidado } \\
\text { utilizados pelos auxiliares e } \\
\text { técnicos de enfermagem que } \\
\text { trabalham em um Centro de } \\
\text { Material e Esterilizaçáo. } \\
\end{array}$ & Pesquisa descritiva & $\begin{array}{l}\text { Investigou a congestão entre os } \\
\text { trabalhadores e os gestores na } \\
\text { discussão e elaboração de açóes de } \\
\text { melhoria das condiçóes laborais } \\
\text { para construir um ambiente } \\
\text { seguro. }\end{array}$ & 03 \\
\hline
\end{tabular}

Fonte: Artigos coletados na Biblioteca Virtual em Saúde, em janeiro de 2017. 
Nesse quadro os artigos selecionados foram separados por seus títulos, seus objetivos, seus dados evidenciados e seu nível de evidência. A análise foi baseada nos níveis 3: evidências de estudos quase-experimentais; 4: evidências de estudos descritivos (não experimentais) ou com abordagem qualitativa; e 6: evidências baseadas em opiniōes de especialistas.

Os desenhos dos estudos envolveram revisão integrativa; pesquisa descritiva, de abordagem qualitativa; estudo qualitativo; abordagem indutiva; pesquisa de campo; pesquisa descritiva de abordagem qualitativa; pesquisa descritiva, transversal; pesquisa descritiva e exploratória com abordagem qualitativa; pesquisa exploratória de caráter retrospectivo; pesquisa descritiva e exploratória, com abordagem quantiqualitativa.

A quinta etapa consistiu na realização da interpretação e discussão dos dados e resultados encontrados que estavam relacionados com o referencial teórico. Com os estudos coletados na revisão integrativa, obtivemos a unidade temática.

\section{Discussão}

Através do método proposto, procurou-se conhecer os resultados relacionados aos riscos ocupacionais do pessoal de enfermagem em ambiente hospitalar ${ }^{9,15}$.

Para isso, foram utilizados os resultados para reunir e sintetizar os resultados de pesquisas sobre o tema de forma sistemática e ordenada e posteriormente discutir propostas de estratégias com vistas a utilizar os conhecimentos adquiridos e propor intervençóes para atender à saúde do trabalhador de enfermagem, confrontando riscos profissionais na sua prática de trabalho ${ }^{22,23}$.

Partindo dessa produção, pode-se inferir que existe maior freqüência de exposição a riscos ambientais e, consequentemente, de acidentes de trabalho (AT) entre os trabalhadores de enfermagem, ou seja, enfermeiros, técnicos e auxiliares de enfermagem quando comparados a outras categorias profissionais da área de saúde ${ }^{4,8}$.

Isso decorre da complexidade do processo de trabalho de enfermagem, da presença constante de riscos ocupacionais e do fato de que essa categoria profissional continua estando o maior tempo ao lado do paciente, bem como pelo tipo de procedimentos realizados pela equipe de enfermagem ${ }^{10,11,16}$.

Estudos avaliados dos acidentes sofridos pelos enfermeiros indicaram que estes ocorreram nas primeiras horas de trabalho, o que se explica pelo tipo de atividade realizada pelo profissional no início do atendimento ${ }^{17}$.
Os estudos demonstraram também que o risco envolvendo material biológico afeta principalmente a categoria profissional e se relaciona com a predominância de lesôes causadas por perfuraçóes. Isso decorre do fato de a enfermagem ser a categoria profissional que mais manipula o material biológico $^{12,18,20,23}$.

Além disso, entre os fatores de risco para exposiçáo da equipe de enfermagem, as evidências apontam para a sobrecarga de trabalho vivenciada por esses profissionais como facilitadora da exposição a riscos ambientais ${ }^{2,6,21}$.

Além disso, a falta de recursos humanos e materiais contribui para a exposição dessa categoria profissional. Juntamente com isso, condições de trabalho adequadas são fundamentais para evitar a exposição do trabalhador de enfermagem aos riscos, ainda que essa profissão seja considerada de alto risco ${ }^{4,19}$.

Nesse entendimento, os autores apontam para situaçóes relacionadas a condiçóes de trabalho que podem expor a saúde do trabalhador de enfermagem ao risco de adquirir patologias.

Essas condiçóes podem facilitar erros na assistência prestada aos clientes, sendo elas: dispositivos de segurança insuficientes ou inadequados, manutenção preventiva inadequada, instruçóes de segurança insuficientes ou inadequadas, uso inadequado de equipamentos de proteção pessoal, perigo de acidentes causados por choques ou cortes com objetos, desenho arquitetônico inadequado de trabalhos em geral, reduzida área de trabalho para a tarefa, iluminação inadequada, entre outros ${ }^{7,4}$.

Tais descobertas aludem a pensamentos sobre exposiçóes que podem estar relacionadas a laços de conhecimento ou até mesmo à conscientizaçáo do trabalhador. Dessa forma, os problemas de saúde dos trabalhadores são frutos de um contexto social que precisa ser repensado e avaliado para realçar o capital humano essencial para o sucesso das organizaçóes ${ }^{13,18}$.

Pesquisas mostram que, no momento do acidente, $40 \%$ dos trabalhadores usavam EPI e $60 \%$ não. Observou-se que os funcionários avaliam o procedimento e sentem a necessidade de usar o EPI, sem valorizar a real importância de seu uso para a prevenção de doenças de origem profissional6,14.

Nesse sentido, o trabalhador adota essa postura, desconsidera o risco real e a legislação recomendada que determina que, nas atividades em que o risco ocupacional existe, a utilização de medidas de proteção é necessária e obrigatória ${ }^{5,12}$.

Com isso em mente, é importante implementar espaços de reflexão coletiva, além de sessóes de treinamento que proporcionem aprendizagem e permitam 
ao trabalhador exercer sua cidadania e discutir temas relacionados ao seu processo de trabalho.

É essencial que os trabalhadores de enfermagem assumam uma postura no processo de trabalho, visando à manutenção da saúde e da integridade física ${ }^{2,20}$.

\section{Conclusão}

Ao enfermeiro do trabalho atribui-se de forma significativa no âmbito hospitalar o desenvolvimento de açóes para medidas de segurança, detecção e minimizaçáo dos riscos ocupacionais de acordo com a atividade realizada e os agravos biológicos a que estão expostos os profissionais de enfermagem, com o objetivo de melhorar as condições laborais.

Destaca-se neste estudo a necessidade da difusão do conhecimento acerca da redução do risco biológico como ferramenta para proteção individual e coletiva desses profissionais, visando aumentar a compreensão e o comprometimento quanto à correta proteção individual e tomada de decisão em caso de acidente com exposição a secreçóes corporais, visto que a totalidade dos profissionais de enfermagem ainda não utiliza medidas de biossegurança.

Portanto, é necessário o incentivo por parte dos gestores das instituiçóes de saúde e a criação de açóes educativas baseadas nas normas de biossegurança, visando à efetividade na prática de novas estratégias que assegurem a proteção do profissional enfermeiro.

Nesse sentido, sabemos que a única forma de consolidar novas estratégias se dará por meio da mudança de comportamento do profissional, e a partir dessa mudança serão colocadas em prática medidas que visem à sua proteção, à do paciente e à do próprio ambiente de trabalho.

Espera-se que este trabalho contribua para enfatizar a extrema relevância do enfermeiro no trabalho de capacitação e orientação da sua equipe a respeito da importância da prevençáo de agravos relacionados à exposiçáo ao risco biológico.

Torna-se importante ainda dizer que, além de contribuir para a saúde do profissional de enfermagem, as orientaçóes dadas pelo enfermeiro do trabalho não se limitam ao espaço físico da organização onde trabalha, pois os trabalhadores se tornam multiplicadores e levam as informaçóes aprendidas para suas famílias e seus grupos de convivência, em que permite dizer, que o enfermeiro do trabalho atua na coletividade, ao buscar a segurança, o bem-estar e a qualidade de vida dos indivíduos, seja dentro ou fora do ambiente hospitalar.
Este artigo demonstra a necessidade de implementar momentos de educação permanente, focalizando a prática reflexiva, pois o campo da saúde do trabalhador, por vezes, se concentra em treinamentos específicos em que o trabalhador recebe instruçóes sobre como proceder e se comportar.

\section{Referências}

1. Balsamo AC, Barrientos DS, Rossi JCB. Estudo retrospectivo dos acidentes de trabalho com exposiçáo a líquidos corporais humanos ocorridos nos funcionários de um hospital universitário. Rev Med HU-USP. 2000;10(1):39-45.

2. Canini SRMS, Gir E, Hayashida M, Machado AA. Acidentes perfurocortantes entre trabalhadores de enfermagem de um hospital universitário do interior paulista. Rev Lat Am Enfermagem. 2002;10(2):172-8.

3. Marziale MHP, Nishimura KYN, Ferreira MM. Riscos de contaminação ocasionados por acidentes de trabalho com material pérfuro-cortante entre trabalhadores de enfermagem. Rev Lat Am Enfermagem. 2004;12(1):36-42.

4. Buschinelli JT. Manual de orientação sobre controle médico ocupacional da exposição a substâncias químicas. São Paulo: Fundacentro; 2014.

5. Goiás. Secretaria de Estado da Saúde. Coordenação Estadual de Controle de Infecçáo Hospitalar. Programa de prevenção e assistência ao acidente profissional com material biológico. Goiânia: Secretaria de Estado da Saúde; 2003.

6. Garner JS. Hospital infection control practices advisory committee. Guideline for isolation precautions in hospitals. Infect Control Hosp Epidemiol. 1996;17(1):53-80.

7. Nakatani, AYK. Processo de enfermagem: uma proposta de ensino através da pedagogia da problematização. Rev Eletr Enf. 2002;4(2):53-45.

8. Baggio MCF, Marziale MHP. A participação da enfermeira do trabalho no programa de conservação auditiva. Rev Lat Am Enfermagem. 2001;9(5):97-9.

9. Souza MT, Silva MD, Carvalho R. Integrative review: what is it? How to do it? Einstein (São Paulo). 2010;8(1):102-6.

10. Silva PLN, Carvalho LM, Mendonça JMG, Gonçalves RPF, Souto SGT, Torres MR. Análise dos acidentes de trabalho na equipe de enfermagem: uma revisão integrativa. Rev Fundam Care. 2016;8(4):5163-76.

11. Silva FFA, Farias HNCF, Costa RHS, Souza NL, Carvalho JBL, Silva RAR. Riscos de acidentes com materiais perfurocortantes no setor de urgência de um hospital público. Rev Fundam Care. 2016;8(4):5074-9.

12. Donatelli S, Vilela RAG, Almeida IM, Lopes MGR. Acidente com material biológico: uma abordagem a partir da análise das atividades de trabalho. Saude Soc. 2015;24(4):1257-72. 
13. Albuquerque SGE, Castro RD, Ferreira GLS, Oliveira KL. Fatores de risco à segurança do enfermeiro na unidade de terapia intensiva de um hospital geral. Rev Bras Ciên Saúde. 2015;19(2):135-42.

14. Andrade AL, Silva MZ, Netto MT. Clima de Segurança no Trabalho Hospitalar: adaptação de medida (ClimaSeg-H). Aval Psicol. 2015;14(2):261-71.

15. Morais EM, Fontana RT. A unidade dialítica como um cenário de exposição a riscos. Rev Fundam Care. 2014;6(2):539-49.

16. Loro MM, Zeitoune RCG, Guido LA, Silva RM, Kolankiewicz ACB. Riscos ocupacionais e a saúde do trabalhador de enfermagem - buscando evidências. Rev Fundam Care. 2014; 6(4):1610-21.

17. Julio RS, Filardi MBS, Marziale MHP. Acidentes de trabalho com material biológico ocorridos em municípios de Minas Gerais. Rev Bras Enferm. 2014;67(1):119-26.

18. Barboza GV, Cortez EA, Valente GSC. O enfermeiro do trabalho na identificação dos riscos ocupacionais em medicina hiperbárica. Rev Pesqui Cuid Fundam. 2014;6(1):320-32.
19. Nowak NL, Campos GA, Borba EO, Ulbricht L, Neves EB. Fatores de risco para acidentes com materiais perfurocortantes. O Mundo da Saúde. 2013;37(4):419-26.

20. Machado MRM, Machado FA. Acidentes com material biológico em trabalhadores de enfermagem do Hospital Geral de Palmas (TO). Rev Bras Saúde Ocup. 2011;36(124):274-81.

21. Oliveira JM, Santos PF, Feliciano RG, Assis MM, Cortez EA, Valente GSC. Riscos e doenças ocupacionais do docente universitário de enfermagem: implicaçôes na saúde do trabalhador. Rev. Pesqui Cuid Fundam. 2013;5(1):3267-75.

22. Santos SS, Costa NA, Mascarenhas MDM. Caracterização das exposiçóes ocupacionais a material biológico entre trabalhadores de hospitais no município de Teresina, estado do Piauí, Brasil, 2007 a 2011. Epidemiol Serv Saude. 2013;22(1): 165-70.

23. Espindola MCG, Fontana RT. Riscos ocupacionais e mecanismos de autocuidado do trabalhador de um centro de material e esterilização. Rev Gaucha Enferm. 2012;33(1):116:23.

\section{Como citar este artigo:}

Jesus CS, Pinto IS, Reis JLB, Fernandes J, Santos R, Soares ES. Atuação do enfermeiro do trabalho na redução de riscos biológicos no âmbito hospitalar. Rev. Aten. Saúde. 2017;15(54):100-107. 